\title{
Association of Insulinoma and Type 2 Diabetes Mellitus
}

\author{
Hassan Ouleghzal, ${ }^{1,}{ }^{*}$ Tarik Ziadi, ${ }^{2}$ Mohammed Menfaa, ${ }^{3}$ and Soumia Safi ${ }^{1}$ \\ ${ }^{1}$ Endocrinology Department, Military Hospital Moulay Ismail, Meknes, Morocco \\ ${ }^{2}$ Radiology Department, Military Hospital Moulay Ismail, Meknes, Morocco \\ ${ }^{3}$ Visceral Surgery Department, Military Hospital Moulay Ismail, Meknes, Morocco \\ "Corresponding author: Hassan Ouleghzal, Endocrinology Department, Military Hospital Moulay Ismail, Meknes, Morocco. Tel: +212-0661099517, E-mail: \\ hassan.ouleghzal@gmail.com
}

Received 2016 May 24; Revised 2016 September 20; Accepted 2016 October 24.

\begin{abstract}
The association of diabetes mellitus and insulinoma is unusual. We are reporting the case of a 58 years old patient having diabetes mellitus type 2 for several years. This patient was well balanced with oral anti-diabetic treatment. However, the diagnosis of insulinoma was discussed due to recent episodes of hypoglycemia that persisted even after stopping the treatment. Abdominal CT allowed the topographic diagnosis. The patient underwent a caudal pancreatectomy. Furthermore, the postoperative period shows that the diabetes mellitus requires the oral anti-diabetic treatment and basal insulin have to be stable. Then, the occurrence of hypoglycemia in the diabetic mellitus type 2 and, especially the persistence after discontinuation of therapy, suggest the unusual diagnosis of insulinoma as illustrated in our observation.
\end{abstract}

Keywords: Hypoglycemia, Insulinoma, Type 2 Diabetes Mellitus

\section{Introduction}

Insulinoma is a rare neuroendocrine tumor, almost exclusively pancreatic, benign and solitary in $90 \%$ of cases. Its association with diabetes mellitus is unusual, with only very few cases reported in literature $(1,2)$, and usually, including our case, insulinoma have a benign character (3). The occurrence of the episodes of hypoglycemia in type 2 diabetes mellitus is more typically due to treatment by hypoglycemian sulfonylurea which requires a dose reduction. But the persistence of those episodes, even after stopping the treatment, suggest the diagnosis of a possible association with an insulinoma, as illustrated the case of our patient.

\section{Case Presentation}

A 58- year- old man, with an 8 year history of diabetes was referred to us for evaluation of hypoglycemia. He had been taking both metformin ( $2 \mathrm{~g}$ ) and gliclazide (60 $\mathrm{mg}$ ) daily. The patient presented with recurrent hypoglycemia which had persisted even after discontinuation of antidiabetic drugs.

Clinical examination revealed a BMI of $31 \mathrm{~kg} / \mathrm{m}^{2}$ and his weight had increased by 5 kilograms during the last 6 months. Physical examination was normal and blood pressure was 130/75 mmHg.

Laboratory tests showed glycated hemoglobin ( $\mathrm{Hb}$ $\mathrm{A} 1 \mathrm{C})$ of $5.3 \%$, renal and hepatic functions, serum calcium and phosphorus levels, serum cortisol level (8 am), parathyroid hormone (PTH), pituitary function tests and Metanephrines were normal.

We recorded one episode of fasting hypoglycemia, but the patient remained clinically asymptomatic at serum glucose level $60 \mathrm{md} / \mathrm{dL}$ and other episodes of hypoglycemia was also noticed, especially at night, with inappropriate insulin levels of up to $46 \mathrm{IU} / \mathrm{mL}$ (normal value of 2.6 to $24 \mathrm{mIU} / \mathrm{L}$ ) (Table 1 ). The fasting test had not been performed.

An abdominal CT showed an isodense rounded mass with regular contour measuring $18 \mathrm{~mm}$ (longest diameter) in the posterior part of the pancreas, which became enhanced after contrast injection. A complementary MRI was indicated to better define the contour of the tumor (Figures 1, 2). The patient underwent corporeo-caudal pancreatectomy. Pathology revealed benign insulinoma. High blood glucose levels returned to the normal postoperatively and the patient was treated with oral anti-diabetic agents and and basal insulin.

\section{Discussion}

Insulinoma is a rare neuroendocrine tumors, almost exclusively pancreatic. Those tumors are clinically the results of hypoglycemia which mainly occur while fasting. Due to the lack of specific clinical symptoms, diagnosis can be relatively delayed. This diagnostic is even longer delayed with pre-existing diabetes mellitus patient. Hypoglycemia's are generally associated with treatment (sulfonylurea's), it will be considered only after the recurrence 
Table 1. Plasma Glucose and Insulin Levels in Follow Up

\begin{tabular}{|c|c|c|c|c|c|}
\hline Temps & $\mathbf{0 8 ~ h}$ & $13 \mathrm{~h}$ & $22 \mathrm{~h}$ & $\mathbf{0 2} \mathbf{h}$ & $\mathbf{0 5 ~ h}$ \\
\hline Plasma glucose: $\mathrm{N}: 0,70$ - 1,10 g/L & 0.35 & 0.55 & 0.71 & 0.30 & 0.29 \\
\hline Insulin : N: 2,6 - 24 mUI/L & 40 & 32 & 28.3 & 46 & 41.9 \\
\hline C-peptid: N: 0,9 -3,2 ng/ml & 9.3 & & & & \\
\hline
\end{tabular}

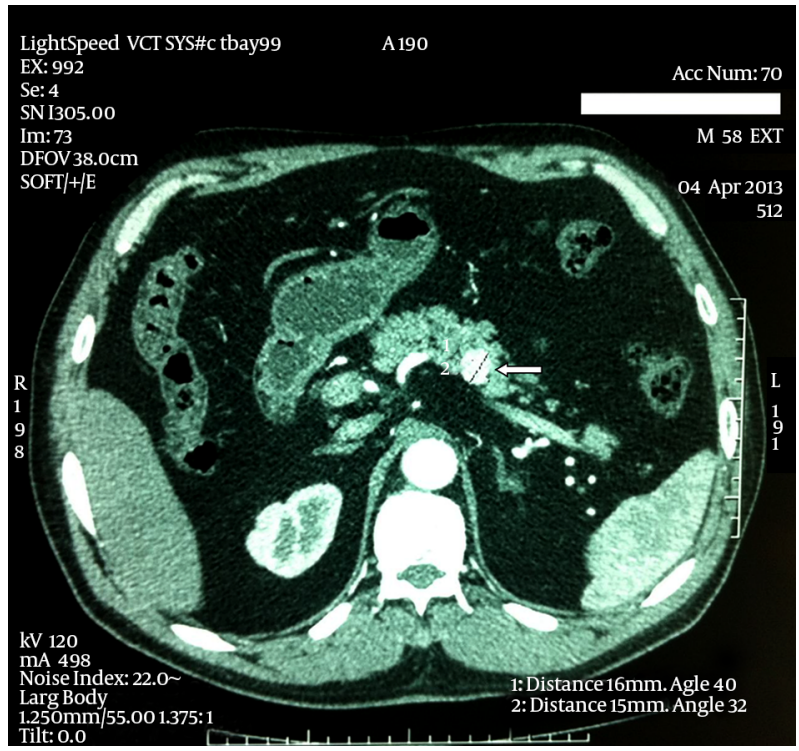

Figure 1. Abdominal CT Showing an Isodense Tumor in the Posterior of the Pancreas, Measuring $18 \mathrm{~mm}$, Rounded, with Regular Contours and Taking Strong Contrast after Injection of Iodine

of hypoglycemia in patients following discontinuation of oral antidiabetic medications and once others causes of hypoglycemia eliminated such as renal failure, advanced liver disease, hypoadrenocorticism, hypopituitarism.

Biologically, the presence of hypoglycemia with inadequately high C-peptide and insulin levels evokes the diagnosis (4) such as the case of our patient. In doubtful cases, prolonged fasting test, up to 72 hours, can be ordered $(5,6)$.

The localization of insulinoma is often very difficult due to the small size of the tumor, echo endoscopy is the reference examination with a sensitivity of around 80\% - 93 $\%$ (7), combined with the scanner, this sensitivity of $100 \%$ can be achieved (8). When the tumor is not found with CT and abdominal MRI, scintigraphy using a receptors agonist of the labeled GLP-1 with Indium-111 seems very promis$\operatorname{ing}(9)$.

For our patient, the diagnosis of insulinoma was relatively easy, it was observed in the abdominal CT. A complementary MRI was needed to confirm the presence of tumor.

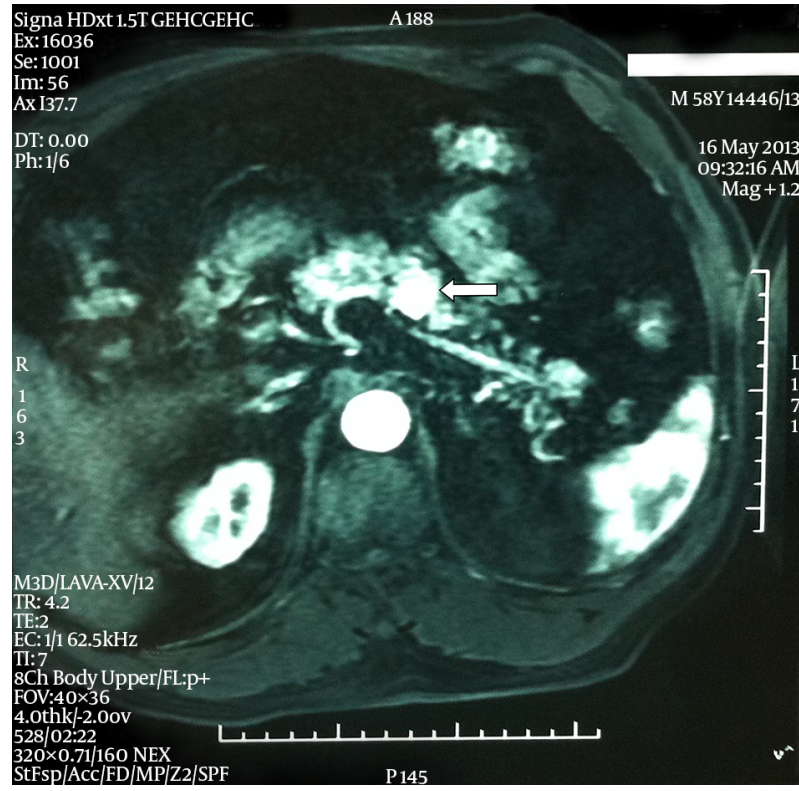

Figure 2. Abdominal MRI Showing an Abnormal Nodular Signal, Oval, well Limited, Measuring $16 \mathrm{~mm}$, Raising to the Arterial Phase in Respect to the Pancreatic Duct and the Splenic Vein

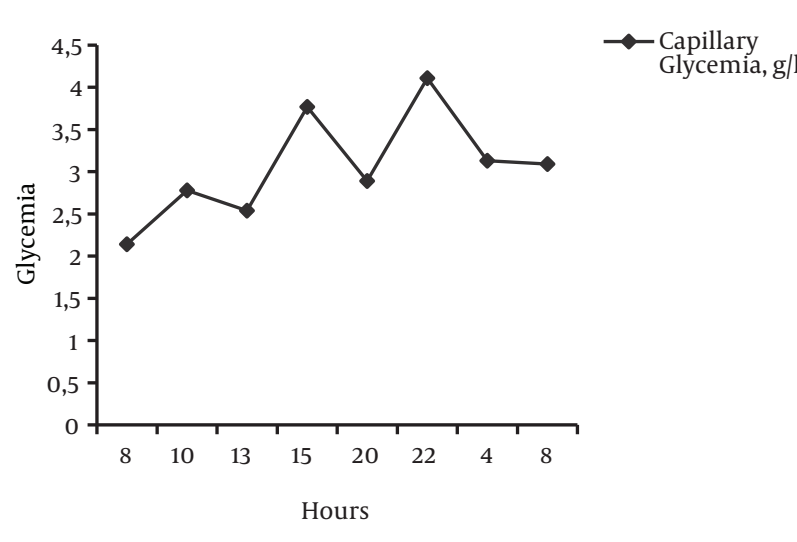

Figure 3. Spontaneous Glycemic Cycle 15 Days After Surgery

In $5-10 \%$ of individuals, insulinoma is integrated as part of multiple endocrine neoplasia (MEN) type 1.The search for othercomponents of MEN1 was negative in our 
patient. The treatment of insulinoma is surgical. Enucleation when possible is preferable for a wider resection area. Because of the location and reports of the tumor, our patient underwent corporeo-caudal pancreatectomy. Endoscopic resection may be considered when the tumor is small, in an exterior position and corporeo-caudal location (10), resumption of anti-diabetic treatment is necessary after surgery. In cases of insulinoma associated with type 2 diabetes as reported by Svartberg, all patients returned to diabetic state after surgery. There could be a possible association between insulinoma and family history of diabetes. Analysis of family history of diabetes in a series of insulinomas highlights that one-third of subjects had an antecedent case of diabetes in their family (11).

In a specific situation such as contraindication after surgery or incomplete excision, medical treatment of hypoglycemia can be suggested, resting on diazoxide verapamil, lanreotide or dextrose perfusions. This treatment usually controls the hypoglycemia transiently.

In case of single tumor, with benign character, like our patient, the possibility of recovery is between 75 to $98 \%$ and survival percentage without relapse is more than 90 $\%$ after 5 years (6). The association with diabetes mellitus does not alter the prognosis.

\subsection{Conclusion}

The occurrence of hypoglycemia in diabetic type 2 patients, and in particular its persistence after discontinuation of therapy, suggests the diagnosis of unusual insulinoma.

\section{Footnote}

Conflict of Interest: The authors declare no conflict of interest.

\section{References}

1. Lei WY, Wang TE, Chen TL, Chang WH, Yang TL, Wang CY. Insulinoma causing hypoglycemia in a patient with type 2 diabetes. J Formos Med Assoc. 2007;106(5):392-6. doi: 10.1016/S0929-6646(09)60324-7. [PubMed: 17561474].

2. Schmitt J, Boullu-Sanchis S, Moreau F, Drui S, Louis B, Chabrier G, et al. Association of malignant insulinoma and type 2 diabetes mellitus: a case report. Ann Endocrinol (Paris). 2008;69(1):69-72. doi: 10.1016/j.ando.2007.11.002. [PubMed: 18291348].

3. Svartberg J, Stridsberg M, Wilander E, Andersson DE, Eriksson B. Tumour-induced hypoglycaemia in a patient with insulin-dependent diabetes mellitus. J Intern Med. 1996;239(2):181-5. [PubMed: 8568488].

4. Vezzosi D, Bennet A, Fauvel J, Caron P. Insulin, C-peptide and proinsulin for the biochemical diagnosis of hypoglycaemia related to endogenous hyperinsulinism. Eur J Endocrinol. 2007;157(1):75-83. doi: 10.1530/EJE-07-0109. [PubMed: 17609405].

5. Heni M, Schott S, Horger M, Dudziak K, Thamer C, Haring HU, et al. [A rare cause of hypoglycaemia in a patient with type 2 diabetes]. Dtsch Med Wochenschr. 2009;134 Suppl Falldatenbank:F2. doi: 10.1055/s0028-1082826. [PubMed: 19235687].

6. Cazabat L, Chanson P, editors. Hypoglycémie et insulinome. Annales d'endocrinologie. 2009; Elsevier; pp. 2-11.

7. Noone TC, Hosey J, Firat Z, Semelka RC. Imaging and localization of islet-cell tumours of the pancreas on CT and MRI. Best Pract Res Clin Endocrinol Metab. 2005;19(2):195-211. doi: 10.1016/j.beem.2004.11.013. [PubMed: 15763695].

8. McLean AM, Fairclough PD. Endoscopic ultrasound in the localisation of pancreatic islet cell tumours. Best Pract Res Clin Endocrinol Metab. 2005;19(2):177-93. doi: 10.1016/j.beem.2004.11.012. [PubMed: 15763694].

9. Christ E, Wild D, Forrer F, Brandle M, Sahli R, Clerici T, et al. Glucagonlike peptide-1 receptor imaging for localization of insulinomas. J Clin Endocrinol Metab. 2009;94(11):4398-405.

10. Abboud B, Boujaoude J. Occult sporadic insulinoma: localization and surgical strategy. World J Gastroenterol. 2008;14(5):657-65. [PubMed: 18205253].

11. Priestley JT. Hyperinsulinism. Ann R Coll Surg Engl. 1962;31:211-28. [PubMed: 13986185]. 